\title{
The Effectiveness of a Training Program in Developing the Linguistic and Musical Intelligence among University Students
}

\author{
Hanan Abdul Hamid Al-Anani and Amal Abdullah Al Masri \\ Princess Alia University College, \\ Al-Balqa Applied University, Jordan
}

\begin{abstract}
This study included two parts: the first is a descriptive survey study which was aimed at assessing the scores of musical and linguistic intelligence in a sample of seventy-five (75) female students and the differences that were attributed to the level of study, the second part is a semi-experimental study whose aim was to assess the linguistic and musical intelligence and the effectiveness of a training program in their development among fifty-two (52) female students from Child Education and English language and its literature. After using the means and the t-test and the two-way analysis of variance (ANOVA), the results were as follow: the linguistic and musical intelligence scores in the survey study were medium, there were no significant differences in the linguistic and musical intelligence attributable to the academic level, the scores of musical and linguistic intelligence in the pretest were medium, and in the post-test they were high, significant differences were also shown in the linguistic and musical intelligence (with its dimensions creativity and excellence) attributed to the training program. No significant differences appeared in linguistic intelligence and musical taste attributed to the students' specialization and to the interaction between the specialization and the training program. However, significant differences were found in linguistic intelligence and musical creativity which may have been due to the specialization of the students in Child Education.
\end{abstract}

Keywords: linguistic intelligence; musical intelligence; child education; English language; English literature.

\section{Introduction}

In light of the tremendous and rapid progress in the field of science and technology, and various economic, social and political areas, attention to individuals, especially the students, is a humanitarian and national duty because they are the leaders of tomorrow, and they will be expected to support the development and progress of their country. One of the methods of caring for students in the development of their intelligence are the linguistic and musical 
intelligence, because they have positive effects on their mental, emotional, social and physical development as well (Hassan, 2006).

The linguistic and musical intelligence belong to the theory of multiple intelligences advocated by Gardner (1999). He explained that it is based on several grounds that these intelligences can be refined by participating in a kind of activity appreciated by culture and that individual growth in such activity follows a developmental pattern. Mozart was four years old when he began to compose music. His experience and abilities grew with age; however, it seems that experience or sufficiency in mathematics with a different path does not appear as early as the ability of music composition. Many mathematical and scientific ideas have emerged in adolescents, as is the case with Pascal (Hassan, 2006). It can also be said that an individual can become a successful novelist at the age of 50, but Gardner believes that multiple intelligences operate in isolation from each other; someone may excel in a specific skill such as reading but fail in mathematics. Every capacity of knowledge is logically intelligent, that is, people can show different levels of efficiency and skill through various types of intelligence (Hussein, 2005). Gardner (1999) stated that multiple intelligence patterns are concentrated in specific regions of the brain, and are characterized by their ability to operate independently, or combined as needed and that most people can improve their intelligence if they are appropriately encouraged (AlOmri, 2009).

Based on the above, it is possible to develop multiple intelligences among individuals, including linguistic and musical intelligence, and due to the lack of studies which focus on linguistic and musical intelligences in the dimensions of taste and creativity, this study was intended to develop these two types of intelligence among female students of Child Education and English language and literature specializations at the Princess Alia University College.

\section{Study problem}

Despite the importance of studies that dealt with multiple intelligences, only a few of them focused on both musical and linguistic intelligence. Thus, the problem of the present study was determined by revealing the degree of musical and linguistic intelligence and the differences in these two intelligences in terms of the level of study and the effectiveness of a training program based on the theory of multiple intelligences in improving linguistic and musical intelligences among female students of Child Education and English language and its literature.

\section{The study questions}

The researchers seek to answer the following questions:

1. What are the degrees of linguistic and musical intelligence and their dimensions among female students of Child Education and English language and its literature?

2. Are there significant differences in linguistic and musical intelligence attributed to the academic level (first year $\mathrm{v} / \mathrm{s}$ fourth year)?

3. What are the linguistic and musical intelligence scores of the students before and after the application of the program? 
4. Are there significant differences in linguistic intelligence attributed to the training program and specialization and interaction between them?

5. Are there significant differences in the linguistic creativity attributed to the training program, specialization, and interaction between them?

6. Are there significant differences in the literary taste attributed to the training program and specialization and interaction between them?

7. Are there significant differences in musical intelligence due to the program, specialization, and interaction between them?

8. Are there significant differences in musical creativity due to the program, specialization, and interaction between them?

9. Are there significant differences in the musical taste attributed to the program and specialization, and interaction between them?

\section{The importance of this study}

The importance of the topic

The search for musical and linguistic intelligence is new, since linguistic intelligence lies in the left half of the brain, while both the spatial, musical and social intelligence exist in the right half of the brain (Hassoun, 2010). The development of linguistic and musical intelligence contributes to an increase in the efficiency of the human mind.

The importance of the target group

Adolescence is the period during which individuals grow mentally, emotionally, socially and physically (Melhem, 2004). The majority of the university students were in their late stage of adolescence, which is a stage of transition to adulthood and are moving towards family life.

Scientific and applied importance

This study can add even modest information to the theoretical literature in the field, and this study can also draw the attention of educators to the importance of linguistic and musical intelligence, and the need to use training programs for their development. This study can also be a motivation for researchers to conduct further studies in the field of linguistics and musical intelligence among other age groups.

\section{Study limits}

This study is determined by its subject matter and the individuals that the study has been applied to them as specified by the instrument, and the time in which it was conducted, which is the first semester of 2016-2017.

\section{The terminology of study and procedural definitions}

Al-Maharmeh and Homedan (2017) finds that linguistic intelligence is the intelligence of words and the ability to read, write, speak and tell stories. Linguistic intelligence is defined as the ability to write, judge, and express the degree to which the student obtains the measure of linguistic intelligence. Linguistic intelligence includes two dimensions: language creativity and literary tasting. Language creativity is the ability to produce language and literature such as the ability to write a story, essay, play or poem while literary tasting is the ability to sense the beauty of the language and judging it. 
Musical intelligence refers to the individual's ability of musical thinking, and to distinguish different musical tunes as well as the ability to process sounds and tones to generate a musical melody (Sherbini \& Sadik, 2002). Musical intelligence is also defined procedurally as the ability to compose, play, sing, and feel and judge music. This is expressed by the score the student obtains on the musical intelligence scale. Musical intelligence also includes two dimensions: artistic creativity and music tasting. Artistic creativity refers to the ability of the individual to compose and express music while music tasting is the ability to sense, analyze and discriminate between different genres of music.

\section{Theoretical framework}

Scientists have dealt with the mental competencies of man for a long time and reached several theories such as Spearman theory which sees that people differ in the extent of their intellectual energy (Hassoun, 2010). Still, Gardner (1999) argued that traditional theories of intelligence do not properly appreciate human intelligence through traditional intelligence measures, because they rely on a small proportion of mental abilities (Syed et al, 2012).

Gardner (1999) has developed a new theory of intelligence called the theory of multiple intelligences which includes the following: logical-mathematical knowledge which is the ability to organize relationships and use numbers and symbols abstracted skillfully and the ability to think critically (Nelson, 1998), visual-spatial intelligence which is the ability to accurately perceive and analyze the visible world, to identify directions and places, to understand details, and to create mental images of objects (Armstrong, 1999), social intelligence which is the ability to understand others, form relationships with them, and work within the social environment (Fares, 2006), physical and motor intelligence which is the ability to use the body in subtle and varied ways, and includes physical skills such as synergy, balance, and speed (Hamdan, 2006), internal-personal intelligence which refers to the individual's ability to recognize himself, his emotions and goals, and to make his decisions based on his understanding (Deing, 2004) and linguistic intelligence which is the intelligence of words, which shows the ease of dealing with language such as reading, writing and speaking, and the ability to produce language quickly, to appreciate the sense of words, their similarities and differences and this ability is clearly shown in writers, poets, and preachers (Al-Maharmeh \& Homedan, 2017; Khamis, 2005).

Language intelligence is probably the most common type of knowledge because the vast majority of people in the world understand speech, and many know how to read and write. Eastern and western cultures see linguistic knowledge as the best type of knowledge because individuals are affected by people with sizeable linguistic wealth (Sukar \& Ghanem, 2011). As for the strategies of training students on linguistic intelligence, they include repetition, writing, authoring, reading, storytelling, audio recording, games of words, speeches and brainstorming (Hussein, 2005). 
Jabir (2003) states that musical intelligence expresses itself through the ability to diagnose musical tones, sense of artistic stances, and the ringing and rhythm of sounds. One of the skills included in this intelligence is the ability of the individual to play a musical instrument with a variety in terms of speed, rhythm, and melody. This intelligence also has the potential to produce rhythms and tones and enjoy various musical expressions (Sherbini \& Sadik, 2002). Hussein (2003) believes that artistic intelligence means that the individual can perceive and analyze music such as music critic, and the ability to express music like a musician. This kind of intelligence can be detected by exposing the individual to musical tunes or songs. One of the methods of activating musical intelligence is to help the individual possess different styles of artistic activities, understand the frequency of musical tones and analyze the voices of others (Hussein, 2005). People with musical intelligence also have the uncanny ability to remember melodies and a strong tendency to collect CDs (Armstrong, 2003). This intelligence differs from linguistic intelligence in that the latter lies on the left side of the brain while musical intelligence lies on the right side. It also requires continuous and intensive training, and only very few individuals are able to achieve very high proficiency (Anizat, 2006). Linguistic and musical intelligence also have some similarities. Music is an element of a literary text (Abu Laban, 2011). Both types of intelligence include listening skills (Bakri, 2006; Al-Anani, 2007). There are several strategies for training in musical intelligence, such as singing songs, playing musical instruments, and creating new melodies for concepts and words (Shinikat, 2011). This intelligence can be developed through musical stories and improvisations in the field of music, singing and playing (Al-Anani, 2007).

Sukar and Ghanem (2011) believes that linguistic intelligence is crucial because it helps the individual to use written or oral language for a practical purpose such as teaching, listening and understanding news, entertainment, reasoning, and changing thoughts and behaviour. On the other hand, literature is one of the beautiful arts in which the individual feels the beauty of words and literary expressions, and it contributes to the development of individual taste. Thus, taste and creativity together contribute to individual growth and social change. Novels, children's stories, poems, and sermons have a significant influence on individuals and society. Language is the main article for the art of the song and the play as both add a lot of joy and happiness to the hearts of listeners and viewers, and if the language is the main article for the art of song and play, then music is the second main article. Wilson (2000) finds that the pattern and type of music affect the heart and change the brain chemistry. Just as music has a biological nature, it has a social nature, and the roots of singing were found in religious rites, and the music reflects social life with its different rhythms. Therefore, songs of hunting, mourning, war, love, harvest, and children's horror are found in most cultures and societies.

Music can stir up memories, move feelings and shape the mood, and is related to the psychology of the recipient because the individual drops what is inside him on the music, and this may earn him comfort. On the other hand, music helps creativity and sophistication. We can see its effect on the performance of the 
actor, and as linguistic intelligence, musical intelligence with its creativity and taste is reflected positively on the mental health of the individual and society.

\section{Previous studies}

Jumaa, Saafan and Murad (2019) investigated the effectiveness of a program to develop the musical intelligence among the middle stage students in Kuwait. It also aimed to reveal the emotional compatibility among them. The core sample included thirty (30) students from the same study community, divided into two groups: a control group of fifteen (15) students, and an experimental group of another fifteen (15) students. The researchers collected the necessary data by using several means, the most important of which were the musical intelligence scale, the emotional compatibility scale, and the training program. The results showed statistically significant differences between the pre- and post- average levels of the musical intelligence list in favor of the experimental group.

Al-Hayhi (2018) aimed to reveal the effect of using e-learning in developing the multiple intelligence of the English language subject. The sample for this study consisted of forty-six (46) students from the fifth basic class students in the Capital Governorate in Amman. The study sample was randomly distributed into two groups: an experimental group consisting of twenty-five (25) students each and a control group consisting of twenty-one (21) students. The researchers developed the Child Development Intelligence Estimation Scale (MIDAS). The results showed that there were statistically significant differences at the 0.05 significance level between the averages of the performances of the two study groups in favor of the experimental groups who studied using e-learning. In light of these results, the researchers recommended that English language books must include activities that take into account e-learning strategies that develop multiple types of intelligence.

Al-Obaidi (2015) study revealed the effectiveness of the training program in developing musical intelligence among kindergarten children. The sample of the study consisted of sixty (60) children of 5-6 years old (pre-school) in Al Salam Kindergarten in the Second Education Directorate of Karkh, Baghdad. The children were divided into two equal groups: an experimental group consisting of thirty (30) children and a control group consisting of another thirty (30) children. A musical intelligence test for kindergarten children was developed which consisted of three main areas: musical awareness, musical taste, and musical performance. The following conclusions were reached: the kindergarten children suffer from weakness in musical intelligence, children in the experimental group outperformed children in the control group after the application of the training program, the training program had a clear impact, which reflected positively on the children of the experimental group in all the three areas of musical intelligence.

The study of Al-Maharmeh and Homedan (2017) aimed at measuring the level of each type of multiple intelligences among the ordinary and outstanding students in 250 outstanding students, and 250 in Baghdad city schools. The 
results revealed significant differences in the multiple intelligences for the benefit of the distinguished students and the achievement of linguistic intelligence to better grades of the degrees of musical intelligence where the last obtained the lowest ranks. Sukar and Ghanem (2011) identified the linguistic intelligence of students in the preparatory stage and the differences attributed to the variable specialization. The sample comprised of (400) students from Baghdad City Schools. The results showed that the linguistic intelligence among the members of the study was medium, that there are no differences in this intelligence attributed to gender, and differences were found due to specialization in favour of literary specialization.

Momani, Hamouri, Younis, and Al-Qur'an (2011) described the relationship between the level of musical abilities and academic achievement of outstanding students. The study sample consisted of forty-two (42) students purposefully chosen from the ninth grade of the King Abdullah II School of Excellence in Zarqa, Jordan. The results indicated that the performance of students on the test of musical abilities was high in the areas of recall melodies, rhythms and time test. The results also showed that there were no significant differences in artistic talents due to gender. Moreover, Talab (2010) described the effectiveness of a training program in music education based on self-learning in cognitive achievement and the development of some musical skills and music taste among the students of the fourth division, kindergarten department, Faculty of Education, Sohag. Through using the semi-experimental approach, the results showed significant differences in achievement, and in playing, singing, listening, and musical taste, which was attributed to the training program.

Baç and Beyhan (2010) studied the impact of intelligence in supporting projectbased education in students 'achievement and attitudes toward English lessons, which were aimed towards the assessing the impact of multiple intelligences of project-based education in students' achievement and their attitudes towards English lessons in Turkey. The sample of the study consisted of eighty-one (81) students from the primary stage, and they were distributed equally into an experimental group and a control group. The study tools included an achievement test and a scale of student attitudes toward the English language. The study results showed that there were visible differences between the experimental group and the control group, whether in achievement or in attitudes towards the English language. Students who receive their education through the project-based approach found their learning to be more successful. Furthermore, these students exhibited a higher level of motivation compared to those who were taught using the traditional teaching methods.

Gonca (2009) study revealed the impact of the story on children and their intelligence. The sample consisted of eighteen (18) children from Ankara, and the results showed that the training program was effective in improving eight multiple intelligences in these children. Buschik, Shipton, Winner, and Wise (2007) examined the effect of multiple intelligences on increasing the reading motivation of 133 students from the second to the eighth grades. The results showed that the lack of motivation to read was common among students and 
that the most common intelligence was linguistic intelligence and the least common was personal and natural intelligence. The study of Mahmoud and Mahmoud (2009) aimed to find out the effect of summarizing literary and textual subjects in the literary taste of fifth graders. The sample reached (50) students from Iraq, and the results showed that there were statistically significant differences in literary taste for the benefit of the experimental group.

\section{Methodology}

A descriptive approach was used to collect the scores of linguistic and musical intelligence in order to assess and evaluate the differences between these two types of intelligence.

\section{Study participants}

The survey consists of female students from the Child Education and the English language and literature specializations from the first and fourth years of study. Seventy-students was selected from a population of 814 using a random stratified sampling method, as shown in Table 1.

Table 1: Details of participants

\begin{tabular}{lll}
\hline Specialization & Number & Percentage \\
\hline Child education & 44 & $58.67 \%$ \\
English language and literature & 31 & $41.33 \%$ \\
Total & 75 & $100 \%$ \\
\hline
\end{tabular}

The participants for the semi-experimental study were chosen by the intentional method. It consists of 52 female students who wanted to be exposed to the training program, as shown in Table 2.

Table 2: Participants for semi-experimental study

\begin{tabular}{lll}
\hline Specialization & Number & Percentage \\
\hline Child education & 28 & $53.85 \%$ \\
English language and literature & 24 & $46.15 \%$ \\
Total & 52 & $100 \%$ \\
\hline
\end{tabular}

\section{Study tools}

Three tools were used: the linguistic intelligence scale, the musical intelligence scale and the training program based on the multiple intelligence strategies. The tools were also prepared according to the nature of the study and its objectives, and after the researchers had reviewed the literature in the fields of linguistic and musical intelligence.

\section{Study scale}

The scale of linguistic and musical intelligence contains information on the students' specialty and their level of education. The scale of linguistic intelligence included 28 items, while the musical intelligence scale included 24 items. The responses were as follows: Agree (3), Agree to some extent (2) and Disagree (1). To estimate the degrees of linguistic and musical intelligence, the following arithmetic averages were adopted: 3- 2.34 refers to a high degree of 
intelligence, 2.33-1.67 refers to a medium degree of intelligence and 1.66 and lower indicates a low degree of intelligence.

\section{The validity of the scales}

The scales and the items were presented to 10 arbitrators in the field of psychology and childhood and English language in order to get their opinion about the two scales. The scale for linguistic intelligence consisted of 28 items in its initial form. After receiving feedback, an additional item was added, and some other items were amended as proposed by the arbitrators. The scale of musical intelligence consists of 24 items, but amendments were made to them after receiving the arbitrators' comments.

\section{Reliability of the scales}

The reliability of the scale was confirmed using the Cronbach alpha coefficient which was 79.4 for linguistic intelligence and 89.1 for musical intelligence. The scale was re-applied to 20 students. Using the Pearson correlation coefficient, the reliability coefficient for linguistic intelligence was found to be 0.823 , while for musical intelligence was it was found to be 0.865 . Both these values can be considered to be scientifically appropriate as they indicate a high degree of positive correlation between the two sets of participants.

\section{Training program}

The training program was developed to improve the linguistic and musical intelligence of the students. This program is currently being offered to students of Child Education and English language and literature. The program includes a variety of activities that develop linguistic intelligence through speaking, listening, tasting, and creative writing, writing abstracts, reports, and cracking jokes. Activities that develop musical intelligence are listening, tasting and improvisation in composition, playing, singing, and training on Solfège in some children's songs, and performing and judging musical stories.

\section{Program philosophy}

This philosophy is based on the importance of the university's role in education and training. It is not only a place to learn courses, but it is also a suitable environment for the development of different skills, most of which are usually not focused on child education and English. This philosophy is also based on the fact that the university professor is capable of influencing his students, and training them on multiple skills, and providing a suitable environment for learning and training, and by setting educational goals that are translated into non-systematic activities that are often playful and fun. This makes learning experiences more attractive and influential in trainees. The philosophy of the program also emphasizes the importance of the role of multiple intelligences in providing new patterns of learning and training models capable of satisfying the needs of students and caring for them to become more efficient and effective in the scientific and practical fields.

\section{Program planning}

Planning includes the identification of educational experiences, and the analysis of content to curtail concepts including the skills required for development 
among students through general goals and behavioural goals translated into educational positions and activities. Learning, training strategies and educational media are also identified to achieve the program's objectives. The overall objectives of the program were: development of linguistic creativity, development of linguistic taste, development of musical creativity, and the development of musical taste. These goals are achieved through the development of the student's ability to listen, speak, aesthetic judgment, language and musical composition, singing, summarizing, casting, and Solfège performed on some children's songs.

\section{Program content}

This included 58 activities based on the scientific and practical expertise, and actions necessary for the development of linguistic and musical intelligence such as the development of the skills of taste, writing the story and poetry and improvisation in motion and sound and brainstorming to generate ideas, and training to provide musical stories. The researchers also focused on the design of group activities, individual groups according to the content of the program and the need of students, as they also took into account the use of educational and multimedia means such as newspapers and magazines, stories, poetry journals, the approach of creators, and some musical instruments. The time taken for each activity ranged between 60-70 minutes, while the implementation of the program, as a whole, took four months.

\section{Program evaluation}

The program was evaluated through the application of the linguistic and musical intelligence scales to the students and observing them during the performance of the activities.

\section{Semi-experimental study variables}

Independent variables: a specialization and training program based on multiple intelligences strategies in improving linguistic and musical intelligences.

Dependent variables: it includes linguistic intelligence with its taste, linguistic creativity, and musical intelligence with its taste and musical creativity.

\section{Study procedures}

Procedures included the following: view the theoretical literature and previous studies, preparation of the study scales, the researchers conducted a pilot study to verify the scales' validity and reliability, selection of the study members and application of the two scales on the sample of the descriptive study, and conducting a pretest, implementation of the program to the study members, conducting the post-test and finally analyzing the data, using the SPSS program, to extract the results.

\section{Statistical processes}

Mathematical averages were used to know the levels of linguistic and musical intelligence. The t-test to assess the statistically significant differences attributed to the academic level. A two-way analysis of variance was used to identify the significant differences which are attributed to the program and the specialization 
and the interaction between them. The Cronbach alpha and the Pearson correlation coefficients were used to detect the reliability of the scale.

\section{The study results}

What are the degrees of linguistic and musical intelligence of the students in the survey? The results for this question are shown below in Table 3. The results show that the degree of linguistic and musical intelligence in the students was moderate.

Table 3: Mean scores of students in language and music intelligence

\begin{tabular}{llll}
\hline Intelligence & & Arithmetic mean & Degree \\
\hline Linguistic & Creativity & 2.05 & Medium \\
& Tasting & 2.28 & Medium \\
Overall score & & 2.19 & Medium \\
Music & Creativity & 2.02 & Medium \\
& Tasting & 2.18 & Medium \\
Overall score & & 2.11 & Medium \\
\hline
\end{tabular}

Are there statistically significant differences at the level of significance $(\alpha=0.05)$ in the linguistic and musical intelligence, and in their dimensions attributed to the academic level? To answer this question, the t-test was used, and the results are shown in Table 4 . The results show that there are no significant differences in linguistic and musical intelligence and their dimensions attributable to the academic level, where the level of significance of intelligence and dimensions is higher than 0.05 .

Table 4: Results of the t-test for musical and linguistic intelligence

\begin{tabular}{llllll}
\hline Intelligence & $\begin{array}{l}\text { Study } \\
\text { level }\end{array}$ & $\begin{array}{l}\text { Arithmeti } \\
\text { c average }\end{array}$ & $\begin{array}{l}\text { Standard } \\
\text { deviation }\end{array}$ & $\begin{array}{l}\text { Value } \\
\text { of } \mathbf{t}\end{array}$ & $\begin{array}{l}\text { Level } \\
\text { significance }\end{array}$ \\
\hline Creative language & First & 2.05 & 0.29 & 0.031 & 0.975 \\
& Fourth & 2.05 & 0.28 & & \\
Linguistic taste & First & 2.25 & 0.27 & -1.06 & 0.290 \\
& Fourth & 2.31 & 0.22 & & \\
Total degree of & First & 2.21 & 0.25 & -0.712 & 0.479 \\
language intelligence & Fourth & 2.17 & 0.19 & & \\
Creative Music & First & 2.00 & 0.45 & -0.304 & 0.762 \\
& Fourth & 2.04 & 0.39 & & \\
Music tasting & First & 2.20 & 0.48 & 0.666 & 0.507 \\
& Fourth & 2.14 & 0.36 & & \\
Total degree of musical & First & 2.12 & 0.46 & 0.252 & 0.802 \\
intelligence & Fourth & 2.09 & 0.33 & & \\
\hline
\end{tabular}

What are the degrees of linguistic and musical intelligence of students before and after the application of the semi-experimental study? The results are illustrated in Table 5. From Table 5, we can see that all degrees of musical and language intelligence before the application was medium. Furthermore, the artistic creativity achieved the lowest grades followed by linguistic creativity. 
Table 5: Level of linguistic and musical intelligence before and after the application of the semi-experimental study

\begin{tabular}{|c|c|c|c|c|c|}
\hline \multicolumn{2}{|c|}{ Intelligence } & $\begin{array}{l}\text { Arithmetic } \\
\text { mean of the } \\
\text { pretest }\end{array}$ & $\begin{array}{l}\text { Degree for } \\
\text { pretest }\end{array}$ & $\begin{array}{l}\text { Arithmetic } \\
\text { mean of the } \\
\text { post-test }\end{array}$ & $\begin{array}{l}\text { Degree for } \\
\text { post-test }\end{array}$ \\
\hline \multirow[t]{2}{*}{ Linguistic } & Creativity & 1.86 & Medium & 2.51 & High \\
\hline & Tasting & 1.97 & Medium & 2.59 & High \\
\hline \multicolumn{2}{|c|}{$\begin{array}{l}\text { Total degree of } \\
\text { linguistic intelligence }\end{array}$} & 1.22 & Medium & 2.56 & High \\
\hline \multirow[t]{2}{*}{ Music } & Creativity & 1.65 & Low & 2.49 & High \\
\hline & Tasting & 1.88 & Medium & 2.66 & High \\
\hline \multicolumn{2}{|c|}{$\begin{array}{l}\text { Total degree of } \\
\text { musical intelligence }\end{array}$} & 1.78 & Medium & 2.59 & High \\
\hline
\end{tabular}

Are there any statistically significant differences at the 0.05 level and less in linguistic intelligence attributed to the training program and specialization and interaction between them? To answer this question, a two-way analysis of variance was used, and Table 6 illustrates the results. Significant differences were shown in Table 6 in linguistic intelligence, where the value of " $\mathrm{F}$ " 364.0 and the level of significance was (0.000), returning to the arithmetic averages in Table 5 , these differences are shown in favour of post-test, and there were no differences in linguistic intelligence attributable to the specialization or its interaction with the training program.

Table 6: Results of two-way analysis of variance for linguistic intelligence

\begin{tabular}{|c|c|c|c|c|c|}
\hline $\begin{array}{l}\text { Source of } \\
\text { variance }\end{array}$ & $\begin{array}{l}\text { Sum of } \\
\text { squares }\end{array}$ & Df & $\begin{array}{l}\text { Mean of } \\
\text { squares }\end{array}$ & "F" Value & Sig \\
\hline Program & 5.22 & 1 & 5.22 & 364 & $0.000 *$ \\
\hline Specialization & 0.001 & 1 & 0.001 & 0.053 & 0.819 \\
\hline $\begin{array}{l}\text { Program } \\
\text { Specialization }\end{array}$ & 0.360 & 1 & 0.036 & 2.5 & 0.120 \\
\hline Error & 0.68 & 48 & 0.14 & & \\
\hline Corrected total & 6.05 & 51 & & & \\
\hline
\end{tabular}

* Statistical significance at the 0.05 level and less.

Are there any statistically significant differences at the 0.05 level and less in linguistic creativity attributed to the training program and specialization and interaction between them? Again, to answer this question, a two-way variance analysis was used. From the results which are presented in Table 7, significant differences were shown in linguistic creativity where the value of " $F$ " was 173.5 and the level of significance was (0.000), Table 7 also shows that the differences were in favour of the post-test. There were no significant differences due to specialization or the interaction between specialization and the program. 
Table 7: Results of two-way analysis of variance for linguistic creativity

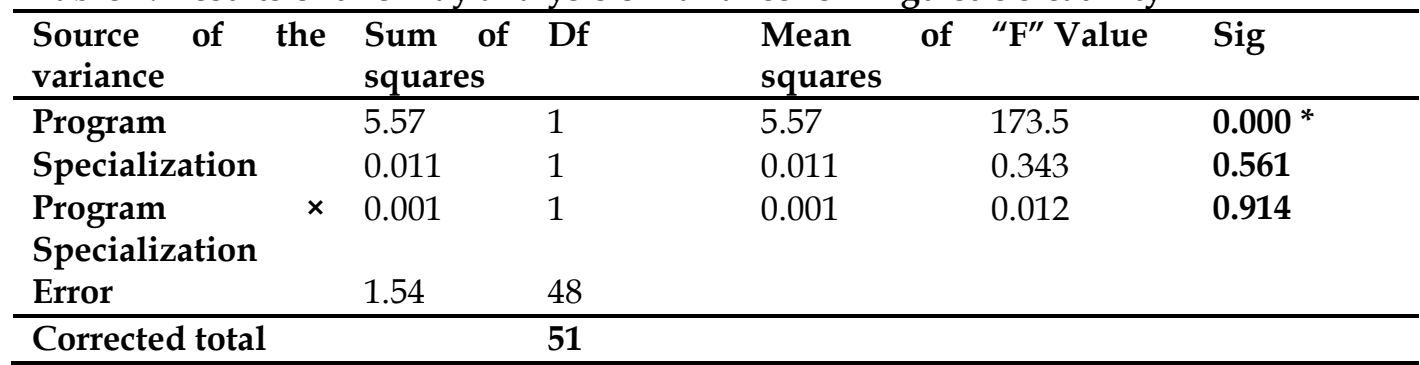

* Statistical significance at the 0.05 level and less.

Are there any statistically significant differences at the 0.05 level and less in the literary taste attributed to the program and specialization and interaction between them? To answer this question, a binary variance analysis was used, as shown in Table 8. Significant differences in literary taste scores were shown in Table 8, where the value of " $F$ " was 289.7 and the level of significance was (0.000) for the benefit of post-test. As was shown in Table 5, there were no significant differences due to specialization, while differences were found in the interaction between the specialization and the program.

Table 8: Results of the two-way analysis of variance for literary tasting scores

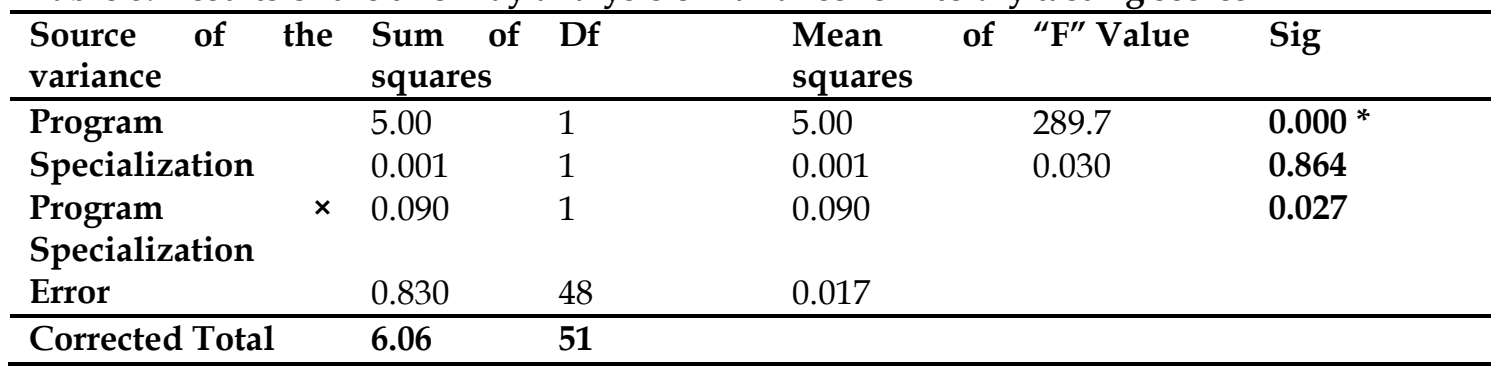

* Statistical significance at the 0.05 level and less.

Are there any statistically significant differences at the 0.05 level and less in musical intelligence attributed to the program and specialization and interaction between them? To answer this question, a binary variance analysis was used, as presented in Table 9.

Table 9: Results of two-way analysis of variance for musical intelligence scores

\begin{tabular}{lllllll}
\hline $\begin{array}{l}\text { Source of } \\
\text { variance }\end{array}$ & $\begin{array}{l}\text { Sum of } \\
\text { squares }\end{array}$ & Df & $\begin{array}{l}\text { Mean } \\
\text { squares }\end{array}$ & of "F" Value & Sig \\
\hline $\begin{array}{l}\text { Program } \\
\text { Specialization }\end{array}$ & 8.39 & 1 & 8.39 & 87.46 & $\mathbf{0 . 0 0 0}$ \\
$\begin{array}{l}\text { Program } \\
\begin{array}{l}\text { Specialization } \\
\text { Error }\end{array}\end{array}$ & 0.481 & 1 & 0.481 & 5.01 & $\mathbf{0 . 0 3 0}$ \\
\hline Corrected Total & 0.005 & 1 & 0.005 & 0.056 & $\mathbf{0 . 8 1 4}$ \\
\hline
\end{tabular}

* Statistical significance at level (0.05) and less.

Significant differences in the musical intelligence are shown in Table 9, where the value of "F" was (87.46) and the level of significance was (0.000) for the benefit of post-test. As shown in Table 5, there were also statistically significant 
differences in the musical intelligence attributed to the specialization. As shown in Table 10, there were no statistically significant differences due to the interaction between specialization and program.

Table 10: Mean scores of musical intelligence by specialization

\begin{tabular}{lll}
\hline Specialization & Accurate averages & \\
\cline { 2 - 3 } Child education & Pretest & Post-test \\
\hline English language & 1.78 & 2.61 \\
\hline
\end{tabular}

Are there any statistically significant differences at the 0.05 level and less in musical creativity attributed to the program and specialization and interaction between them? To answer this question, the two-way analysis of variance was used, as illustrated in Table 11.

Table 11: Results of two-way analysis of variance for musical creativity

\begin{tabular}{|c|c|c|c|c|c|c|}
\hline $\begin{array}{ll}\text { Source } \\
\text { variance }\end{array}$ & the & $\begin{array}{l}\text { Sum of } \\
\text { squares }\end{array}$ & Df & $\begin{array}{l}\text { Mean of } \\
\text { squares }\end{array}$ & "F" Value & Sig \\
\hline Program & & 9.10 & 1 & 9.10 & $\begin{array}{l}63.28 \\
\end{array}$ & $0.000^{*}$ \\
\hline Specialization & & 0.977 & 1 & 0.977 & 6.79 & 0.012 \\
\hline $\begin{array}{l}\text { Program } \\
\text { Specialization }\end{array}$ & $x$ & 0.001 & 1 & 0.001 & 0.010 & 0.920 \\
\hline Error & & 690 & 48 & 0.144 & & \\
\hline Total corrected & & 17.02 & 51 & & & \\
\hline
\end{tabular}

* Statistical significance at the 0.05 level and less.

Significant differences in the degrees of artistic creativity were shown in Table 11 , and these differences were attributed to the training program, where the value of "F" was 63.28 and the level of significance was 0.000 for the benefit of pretest. As was shown in Table 5, there were also significant differences in these grades due to the specialization where the value of " $F$ " was 6.79 and the level of significance was 0.012 . Table 12 shows that differences in the averages of musical creativity were in favour of female students, and there were no differences in the artistic creativity of female students due to the interaction between specialization and the program.

Table 12: Mean scores for musical creativity according to specialization

\begin{tabular}{|c|c|c|}
\hline Specialization & Mathe & \\
\hline & Pretest & Post-test \\
\hline Child education & 1.95 & 2.71 \\
\hline $\begin{array}{l}\text { English Language } \\
\text { literature }\end{array}$ & 1.79 & 2.60 \\
\hline
\end{tabular}

Are there any statistically significant differences at the 0.05 level and less in musical taste attributed to the program and specialization and interaction between them? To answer this question, a two-way analysis of variance was used, as displayed in Table 13. 
Table 13: Results of two-way analysis of variance for music tasting

\begin{tabular}{llllll}
\hline Source of variation & $\begin{array}{l}\text { Sum of } \\
\text { squares }\end{array}$ & Df & $\begin{array}{l}\text { Mean of } \\
\text { squares }\end{array}$ & “F” Value & Sig \\
\hline Program & 7.90 & 1 & 7.90 & 82.66 & $\mathbf{0 . 0 0 0}{ }^{*}$ \\
$\begin{array}{l}\text { Specialization } \\
\text { Program }\end{array}$ & 0.233 & 1 & 0.233 & 2.43 & $\mathbf{0 . 1 2 5}$ \\
$\begin{array}{l}\text { Specialization } \\
\text { Error }\end{array}$ & 0.010 & 1 & 0.010 & 0.100 & $\mathbf{0 . 7 5 3}$ \\
\hline Total corrected & 4.59 & 48 & 0.096 & & \\
\hline
\end{tabular}

* Statistical significance at the 0.05 level and less.

Significant differences in musical taste scores were shown in Table 13, where the value of "F" 82.66 and the level of significance was 0.000 for the benefit of posttest. As was shown in Table 5, there were no statistically significant differences due to specialization or interaction between it and the program.

\section{Discussion of the study results}

The results of the first question showed that the degree of linguistic and musical intelligence and their success was moderate, and this calls for the need to pay attention to them and work on their development by parents, educators and educational institutions in general. The results show that the degree of linguistic and musical creativity is less than that of literary and artistic taste and that the level of linguistic intelligence is higher than the level of artistic intelligence. This result is consistent with reality because creativity is less collective than taste and requires much training and refining the talent until it grows appropriately. This result is consistent with the study of Al-Obaidi (2015), in that it stated that musical intelligence had the lowest scores compared to other ones, and this result also differs from the survey of Jumaa, Saafan, and Murad (2019), where they concluded that the literary taste was low in the sample members. The result also differs from the results of Momani et al. (2011), which showed that students had a high musical intelligence. This result can be explained because their sample consisted of outstanding students whose courses included programs for the development of musical abilities.

No significant differences were found in the linguistic and musical intelligence based on the level of study. This means that all students in the first and fourth levels are similar in these two types of intelligence. This result may be due to students' belonging to different cultural and social environments. The results of the third question showed that all degrees of linguistic and musical intelligence was high after the application of the program, which indicates the impact of the training program, which took care of all dimensions of linguistic and musical intelligence, and raised the motivation of students to learn. While artistic creativity had the lowest scores in the pretest, the music tasting has the highest ratings in the post-test. It may be attributed to the fact that creativity is partly due to training. Talent may exist but may not be visible due to the surrounding environment or the lack of opportunities that develop musical creativity. Musical taste can also be improved by training and changing trends towards music and taste. After applying the program, we saw that the score for musical taste has increased. 
The results indicate significant differences in linguistic and musical intelligence and their dimensions for the benefit of the post-test. This result is due to the training program used in this study, which contained various activities because they have taken the character of the play and fun most of the time, such as writing, improvisation in composition, playing, singing and presenting musical stories and criticizing them. This result is also attributed to the strategies used in the presentation of the program such as repetition, improvisation, narrative, word games and brainstorming, as these strategies contributed to the generation of creative ideas, original behaviour, and critical thinking which is essential for aesthetic judgment. This result is also due to the various means used in the program such as a computer, musical instruments such as Organ, and some visual and audio methods such as newspapers, magazines, display boards, and cylinders. The time to implement the program was appropriate to achieve the study main objectives which were the development of linguistic and musical intelligence in the students. The goal of the program is not professionalism and mastery, but the development of creativity and taste to an appropriate extent in order to help students to employ these acquired skills in self-learning, and to promote the development of linguistic and musical intelligences in young children, whether in kindergartens, schools or at home.

This result is consistent with some studies such as Taleb (2010) and Gonca (2009). This result of the effectiveness of the program in the development of musical creativity is also consistent with the study of Baç and Beyhan (2010), and also partially consistent with Al-Hayhi (2018). It is clear from the results of question 6 that there are significant differences in literary taste due to the interaction of the program with specialization. These differences may be attributed to the differences in the function of the training program.

At the same time, there were significant differences in intelligence and musical creativity due to the specialization toward female Child Education students. This result is because intelligence and creative music need more intensive training than linguistic intelligence because English language students are more concerned with mastering the subject, which affects their concentration in individual practice and the development of their musical intelligence. The results also showed that there are no statistically significant differences in linguistic intelligence in the most general and artistic fields due to the interaction of specialization with the program. This result may be due to the weakness of the differences in intelligence attributed to the students' specialization. There is also a need for further studies in the area of specialty and its interaction with the program to achieve better results that would enrich knowledge in this field.

\section{Conclusion}

This study about the linguistic and musical intelligence and the effectiveness of a training program in their development among Jordanian University students showed that there are statistically significant differences in the linguistic and musical intelligence and their dimensions which were attributable to the study variables. Although the term intelligence is called the distinct mental abilities of individuals that make them unique in their performance from others, there is 
still no accurate and clear definition of intelligence. Generally, we can say that intelligence may be innate or may be acquired from the environment. It is also the ability of the individual to learn from situations, self-development and changing behaviours for the better. There are different types of intelligence, and the students of each type of intelligence are distinguished by specific characteristics that enable them to perform certain tasks and to succeed in them. It also enables them to show high creative capabilities that exceed their ability to perform other works that may not be commensurate with their current capabilities and skills. Each type of intelligence can create a chance of success that differs from the other types. People with linguistic intelligence can use words in highly creative words. They tend to read a lot, have a great taste of poetry and write topics of expression. They are also the ablest to communicate with others effectively and express themselves in the surrounding community. They also have good persuasive skills. On the other hand, people who have musical or rhythmic intelligence deal with music in different ways that makes them aware of the language of music and the meanings it intends to communicate. There is a strong and close relationship between music and feelings, so people who enjoy musical intelligence often enjoy excellent mental health (Carlson et al., 2015).

\section{Recommendations and ideas for further research}

1. Work in the interest of musical education, and aesthetic education since early childhood.

2. Focus on teaching the English language and its arts in interesting ways so that students want to learn it and can become creative.

3. Emphasize the development of creativity and taste of beauty in the child from early childhood, be it at the home, in kindergartens, schools.

4. The media can also contribute to the linguistic and musical intelligence of adults.

5. Conduct semi-experimental research for the development of linguistic and musical intelligence among both male and female kindergarten students.

6. Conduct semi-experimental research to develop linguistic and musical intelligence among students of both sexes and in different disciplines (scientific, literary, etc).

\section{References}

Abu Laban, W. (2011). The concept of tasting and its nature. Retrieved from http://kenanaonline.com/

Al-Anani, H. (2007). Music in Child Education, Amman: Dar Al Fikr.

Al-Hayhi, S. (2018). The Effect of Using E-learning in Developing of the Multiple Intelligences in English Language for the Basic Fifth Grade Male Students in the Capital. Unpublished master thesis, Middle East University, Amman, Jordan.

Al-Maharmeh, L. M. M., Homedan, N. S. I. (2017). Intelligence Observation Amman Arab University Variance Upon Student's Point Of View. European Journal of Business and Social Sciences, 6(6), 128-144.

Al-Obaidi, Z. (2015). The effectiveness of a training program in developing musical intelligence among kindergarten children. Unpublished Ph.D. Dissertation. Baghdad University, College of Education for Girls, Iraq, Baghdad. 
Al-Omri, J. (2009). The Multiple Intelligences and Self-efficacy of talented Students at the Jubilee School, Unpublished Master Thesis, Balqa Applied University, Jordan.

Anizat, S. (2006). The Theory of Multiple Intelligences and Learning Difficulties. Amman: Dar Al Fikr for Publication and Distribution.

Armstrong, T. (1999). Seven types of intelligence: Identifying and developing multiple intelligences, N. Y: New American Library.

Armstrong, T. (2003). Multiple Intelligences in the classroom, Association for prevision and curriculum, Michigan, U.S.A.

Bakri, A. (2006). The effectiveness of a proposed program in the light of the theory of multiple intelligences in the treatment of the difficulties of written expression in the second- grade students, Ph.D., Girls College, Ain Shams University.

Baş, G., \& Beyhan, Ö. (2010). Effects of multiple intelligences supported project-based learning on students' achievement levels and attitudes towards English lesson. International Electronic Journal of Elementary Education, 2(3), 365-386.

Buschik, M., Shipton, T., Winner, L., \& Wise, M. (2007). Increasing reading motivation in elementary, middle school students through the use of multiple intelligences (Master's thesis, Saint Xavier University, Chicago, Illinois). Retrieved from https://files.eric.ed.gov/fulltext/ED498926.pdf

Carlson, E., Saarikallio, S., Toiviainen, P., Bogert, B., Kliuchko, M., \& Brattico, E. (2015). Maladaptive and adaptive emotion regulation through music: a behavioral and neuroimaging study of males and females. Frontiers in Human Neuroscience, 9, Article 466. doi: 10.3389/ fnhum.2015.00466

Deing, S. (2004). Multiple intelligences and learning styles: two complementary dimesions. Teachers College Record, 106(1), 16-23. https://doi.org/10.1111/j.14679620.2004.00322.x

Fares, E. (2006). The effectiveness of a program based on various intelligence in the development of educational achievement and the skills beyond the knowledge of high school students in psychology (Doctoral dissertation, Institute of Educational Studies, Cairo University, Egypt).

Gardner, H. (1999). Intelligence reframed: Multiple intelligences for the 21st century. New York, USA: Basic Books.

Gonca, K. (2009). Various short-story activities for very young learners with multiple tastes. E K e v Academic Review, 13(40), 51-86.

Hamdan, M. (2006). Health of the family and children. Amman, Jordan: Modern Education House.

Hassan, M. (2006). Program for the training of some mental skills and its impact on the level of performance of the piano player (Master's thesis, Faculty of Qualitative Education, University of Menoufia, Egypt).

Hassoun, S. (2010). A Comparative Study of Logical and Spatial Intelligence in Secondary and Distinguished Students and their ordinary peers. Al-Fath Journal, 45(1), 112-136.

Hussein, M. (2005). Early Detection of Multiple Intelligences in Early Childhood. Amman, Jordan: Dar Al-Fikr.

Hussein, M. (2003). Measuring and Evaluating the Capacities of Multiple Intelligences. Amman, Jordan: Dar Al-Fikr.

Jumaa, M., Saafan, M., \& Murad, M. (2019). The effectiveness of a training program to develop musical intelligence in improving emotional compatibility among middle school students in the State of Kuwait. The Arab Journal of Literature and Humanities, 9(9), 185-229. 
Khamis, M. (2005). The effect of multiple intelligences essential teaching program on Jordanian upper basic stage students' paragraph writing ability (Doctoral dissertation. Arab University for Graduate Studies, Amman, Jordan).

Mahmoud, K., \& Mahmoud, A. (2009). The impact of summarizing the topics of literature and texts in the literary taste of students of the fifth grade literary. AlFath Journal, 43(1), 75-91.

Melhem, S. (2004). Developmental Psychology. Amman, Jordan: Dar Al-Fikr.

Momani, M., Hamouri, K., Yunus, N., \& Al-Qur'an, J. (2011). Jordanian Journal of Arts, 4(1), $29-43$.

Nelson, R. (1998). Effective Thinking Skills: Preventing and Managing Personal Problems. London, England: Cassell Education Limited.

Sukar, H., \& Ghanem, H. (2011). Linguistic Intelligence in Preparatory Students. Journal of Educational and Psychological Research, 31(1), 143-170.

Shinikat, F. (2011). Build a scale to detect talented kindergarten children and verifying its effectiveness in a Jordanian sample (Doctoral dissertation, University of Jordan, Jordan).

Sherbini, Z., \& Sadik, Y. (2002). Children above the top. Cairo, Egypt: Arab Thought House.

Salim, S. S. S., Nasir, R., Arip, M. A. S. M., \& Mustafa, M. B. (2012). The Role of Emotional Intelligence on Job Satisfaction among School Teachers. The Social Sciences, 7(1), 125-129. http:/ / dx.doi.org/10.3923/sscience.2012.125.129

Talab, N. (2010). The effectiveness of a proposed training program in music education based on self-learning in cognitive achievement and the development of some musical skills and musical taste among students of the Fourth Division, Kindergarten Division. Unpublished Ph.D., Faculty of Education, Sohag University.

Wilson, G. (2000). The Psychology of Performing Arts, Translation by Shaker Abdul Hamid, Kuwait, Knowledge World, National Council for Culture and Arts, No. 258. 